\title{
MASA RENAL ASINTOMÁTICA COMO PRIMERA MANIFESTACIÓN DE CARCINOMA FOLICULAR DE TIROIDES
}

\author{
J.M. REGOJO BALBOA, D. SÁNCHEZ ZALABARDO, J. RIOJA ZUAZU, \\ J.M. FERNÁNDEZ MONTERO, J. LÓPEZ FERRANDIS, J.J. ZUDAIRE BERGERA, \\ D. ROSELL COSTA, J.E. ROBLES GARCÍA, J.M. BERIÁN POLO
}

Departamento de Urología. Clínica Universitaria. Universidad de Navarra. Pamplona (Navarra).

Actas Urol Esp. 28 (4): 308-310, 2004

\section{RESUMEN}

MASA RENAL ASINTOMÁTICA COMO PRIMERA MANIFESTACIÓN DE CARCINOMA FOLICULAR DE TIROIDES

Las metástasis de carcinoma de tiroides en riñón son raras. Presentamos el $10^{\circ}$ caso, que conocemos publicado, de metástasis tiroidea en riñón y el primero del tipo folicular y asintomático.

Se trata de una paciente de 75 años asintomática, que presenta una masa en el riñón derecho, que se decide realizar nefrectomía parcial derecha. El diagnóstico provisional habla de tumor de células claras renales pero el definitivo es de metástasis de carcinoma folicular de tiroides, descubrimos un estado avanzado de la enfermedad tanto localmente como a distancia.

Las fuentes de metástasis en el riñón así como las técnicas diagnósticas son discutidas en el caso.

PALABRAS CLAVE: Metástasis. Masa renal. Carcinoma folicular. Tiroides.

\section{ABSTRACT}

FOLLICULAR CARCINOMA OF THE THYROID MANIFESTED INITIALLY ASYMPTOM PRIMARY

\section{RENAL NEOPLASM}

Metastases in the kidney are rare, evenmore if primary source is thyroid.

We report the tenth case of metastases in the kidney from thyroid, and it is the first to be follicular type and absolutely asymptom.

Sonography and computerized tomography with suspicion of renal tumour are showed in a asymtom female 75 years old.

Left partial nephrectomy was perfomed, initially it has been pathologically diagnosed as renal clear cells tumour, however the definitive pathologic report showed follicular tumour of thyroid.

Local and systemic stage was discovered with complementary techniques.

Sources of metastases in kidney and diagnoses techniques are discussed. 
$\mathrm{L}$ a gran mayoría de los tumores renales malignos se incluyen dentro del grupo de adenocarcinomas renales primarios. El riñón es asiento poco habitual de las metástasis de tumores originados en otros órganos, pero es excepcional que el primario sea un carcinoma de tiroides. Es el caso que presentamos.

\section{CASO CLÍNICO}

Paciente de 75 años, diagnosticada casualmente por ecografía rutinaria de una masa sólida en polo superior de riñón derecho. Un año y medio después acude a nuestra consulta. No había seguido ningún tratamiento. Permanece asintomática.

\section{Exploraciones radiológicas}

Tórax PA y L: adenopatías calcificadas en mediastino, presencia de algún tracto fibroso aislado en base izquierda.

TAC abdominal: a nivel del polo superior del riñón derecho y en situación interna, se aprecia una masa sólida de unos 5 cm (Figs. 1 y 2), en su crecimiento hacia abajo llega a tocar con el seno renal, creciendo por detrás de las estructuras vasculares.

Tras administración de contraste se aprecia captación intensa, destacando la presencia de una cicatriz central. Los contornos son nítidos y aparece la masa encapsulada con respecto al parénquima renal.

No se aprecian signos de afectación de la vena renal, ni extensión a espacio perirrenal, ni adenopatías.

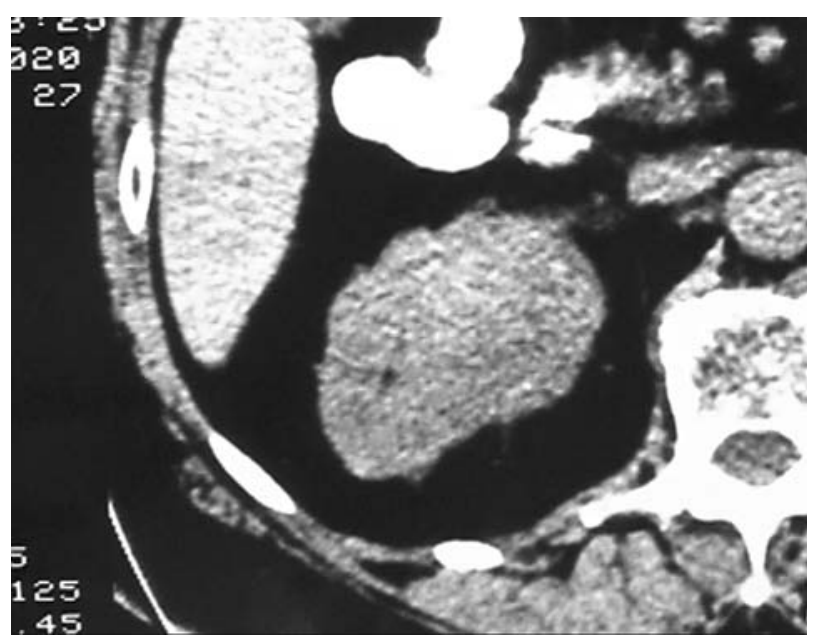

FIGURA 1. TC sin contraste, masa renal derecha.

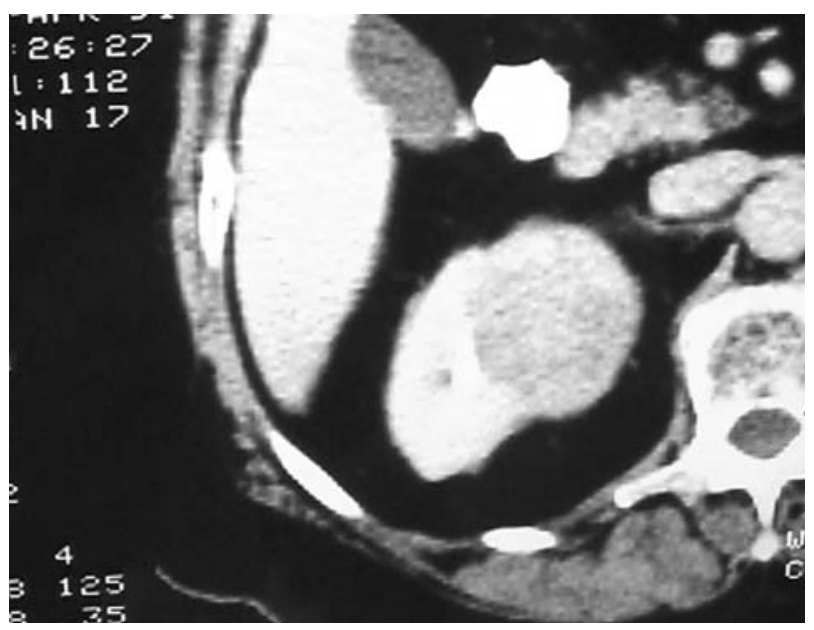

FIGURA 2. TC con contraste, masa renal de $5 \mathrm{~cm}$ de diámetro.

En conclusión, masa renal a determinar, aunque con oncocitoma.

Gammagrafía ósea: aumento de depósitos de captación a nivel de la $5^{\underline{a}}$ vértebra lumbar, y otro a nivel cervical, compatibles con procesos osteodegenerativos.

Tratamiento y Evolución: con el diagnóstico de presunción de adenocarcinoma renal localizado se realiza nefrectomía parcial superior derecha. El diagnóstico intraoperatorio califica al tumor como adenocarcinoma de células claras e indica márgenes de resección libres (T1G1).

Sin embargo, el informe definitivo de anatomía patológica informa que "el tumor renal tiene una diferenciación aparentemente tiroidea. El estudio inmunohistoquímico parece confirmar el origen tiroideo de la tumoración, pues habiéndose utilizado anticuerpos antitiroglobulina, vimentina, AE3-AE1, CAM5.2, alfal antitripsina, calcitonina, enolasa neuroespecífica y antígeno carcinoembrionario. Las células son positivas para antitiroglobulina, CAM5.2 y S-100".

La paciente rehusó realizar exploraciones complementarias y tratamientos inmediatos, pero a los 4 meses comenzó con disfonía y sensación de cuerpo extraño en cuello.

El TAC cervico-torácico evidencia una masa en el lóbulo tiroideo izquierdo de 5-3-6 cm, con crecimiento hacia el mediastino superior, con afectación del istmo tiroideo, adenopatías de 1 cm de diámetro en grupo yugulo-carotídeo medio y un incontable número de lesiones nodulares en ambos campos pulmonares, compatibles con micrometástasis. 
Se realiza tiroidectomía total y vaciamiento ganglionar funcional izquierdo y laringuectomía total por invasión local de la neoplasia.

El informe anatomopatológico confirma la existencia de un carcinoma poco diferenciado folicular de tiroides.

Se le realiza complementariamente una sesión con dosis ablativa de Yodo-131.

\section{DISCUSIÓN}

Siendo el riñón un órgano altamente perfundido (1 litro/min), es un lugar en el que se encuentran pocas metástasis. Sólo en el 4,6-7,6\% de las necropsias de pacientes que fallecen por enfermedad metastásica generalizada existe afectación renal ${ }^{1}$.

Son los tumores linfáticos (linfoma y linfoblastoma) los que más comúnmente metastatizan en parénquima renal. Les siguen por orden de frecuencia los de mama, pulmón, ovario e intestino ${ }^{1,2}$.

Dichas metástasis, generalmente tardias, debutan clínicamente en muy pocas ocasiones. Cuando lo hacen la hematuria o dolor en flanco son los sintomas habituales. Sin embargo, el diagnóstico se realiza en general como consecuencia de pruebas de imagen convencionales realizadas en estudios de extensión de la enfermedad primaria ${ }^{2,3}$.

La técnica de elección para su estudio es el TC, realizándolo con contraste. En las imágenes precontraste, se puede ver la masa isodensa con respecto al parénquima renal, así como con un ligero realce con el contraste $\mathrm{e}^{1,2,5}$.

La arteriografia aunque puede aportar una imagen redondeada e hipovascularizada más característica de lesión secundaria que de tumor primario de riñón, esta técnica está prácticamente en desuso ${ }^{2}$.

$\mathrm{El}$ caso que presentamos es aún más insólito. En la Literatura es el $10^{-}$caso que se publica de metástasis en riñón de carcinoma de tiroides, siendo el $5^{\circ}$ con histología "tipo folicular" y el $1^{\circ}$ que se descubre totalmente asintomático, sin presentar dolor lumbar, hematuria ni clínica hipertensiva ${ }^{1,2,4}$.

Se trata de un caso atípico en su evolución clínica de un carcinoma folicular de tiroides, que debuta según la historia clínica un año y medio antes como masa renal, de crecimiento paulatino, que incomprensiblemente no fue tratada. Cuando lo vimos, no dudamos que fuera un tumor renal primario, de lenta evolución y por lo tanto poco agresivo. El resultado de extensión mediante TAC abdominopélvico y gammagrafia ósea no evidenció metástasis y se realizó tratamiento quirúrgico de intención curativa.

Por otro lado, este caso pone de manifiesto la dificultad que puede presentar el diagnóstico diferencial entre tumor de células claras renales y el folicular de tiroides. En el informe perioperatorio se informó como adenocarcinoma de células claras de riñón. Sólo el estudio minucioso de la pieza y la demostración de positividad de anticuerpos antitiroglobulina, CAM 5.2, S-100, confirmaron el diagnóstico.

La lesión renal se descubrió un año y medio antes. Si hubiera sido intervenida entonces probablemente no se hubiera modificado el pronóstico, pues aunque se han descrito remisiones de la enfermedad mediante nefrectomía y dosis ablativa con yodo ${ }^{5}$, la edad de la paciente y las metástasis a distancia son factores de mal pronóstico de influencia independiente en el cáncer de tiroides ${ }^{6}$. Lo que probablemente hubiera disminuido es el tamaño del primario y la resección quirúrgica hubiera sido sólo tiroidectomía.

Se debe concluir que aunque la mayor parte de las masas renales son tumores primarios, ocasionalmente pueden ser metastásicos y que esta posibilidad debe ser tenida en cuenta.

\section{REFERENCIAS}

1. GAMBOA-DOMÍNGUEZ A, TENORIO-VILLALVAZO A.: Metastatic follicular variant of papillary thyroid carcinoma manifested as a primary renal neoplasm. Endocr Pathol 1999; 10 (3): 256-268.

2. POLACK HM, BANMER MP, AMENDOLA MA.: Other malignant neoplasm of the renal cell parenchyma. Senim Roentgenol 1987; 22: 260-274.

3. INAHARA M, MIKAMI K, TOBE T, SUZUKI H, ITOU H.: A case of thyroid cancer metastazing to the bilateral kidneys. Hinyokika Kiyo 2002 may; 48 (5): 315-317.

4. GRAHAM LD, ROE SM.: Metastatic papillary thyroid carcinoma presenting as a primary renal neoplasm. Am Surgeon 1995; 61 (8): 732-734.

5. SARDI A, AGNONE CM, PELEGRINI A.: Renal metastases from papillary thyroid carcinoma. J La State Med Soc 1992; 144 (9): 416-420.

6. MAZZAFERRI EL, KLOOS RT.: Current approaches to primary therapy for papillary and follicular thyroid cancer. Journal of Clinical Endocrinology and Metabolism 2001; 86 (4): 1447-1463.

Dr. J.M. Regojo Balboa

Servicio de Urología. Clínica Univ. de Navarra

C/ Pío XII, s/n - 31080 Pamplona (Navarra)

(Trabajo recibido el 4 marzo de 2003) 